\title{
Keanekaragaman serangga dan struktur vegetasi pada habitat burung insektivora Lanius schach Linn. di Tanjungsari, Yogyakarta
}

\author{
Insect diversity and vegetation structure of insectivore bird \\ Lanius schach Linn. habitat in Tanjungsari, Yogyakarta \\ Fredy Lala ${ }^{1 *}$, F. X. Wagiman ${ }^{2}$, Nugroho S. Putra ${ }^{2}$ \\ ${ }^{1}$ Balai Pengkajian Teknologi Pertanian Maluku Utara \\ Kompleks Pertanian Kusu, Kota Tidore Kepulauan, Maluku Utara 97800 \\ ${ }^{2}$ Jurusan Hama dan Penyakit Tumbuhan, Fakultas Pertanian, Universitas Gadjah Mada \\ Jalan Flora No.1, Bulaksumur, Yogyakarta 55281
}

(diterima Maret 2013, disetujui Mei 2013)

\begin{abstract}
ABSTRAK
Keanekaragaman serangga dan struktur vegetasi suatu ekosistem adalah dua aspek penting yang mempengaruhi perkembangbiakan burung insektivora. Penelitian bertujuan untuk mengetahui karakteristik habitat asli Lanius schach di Tanjungsari yang meliputi jenis dan komposisi vegetasi serta preferensi burung terhadap serangga mangsa. Pengamatan vegetasi dan serangga menggunakan kombinasi metode jalur dan garis berpetak pada jalur sepanjang $10 \mathrm{~km}$ yang terbagi atas sepuluh titik pengamatan. Penghitungan jenis pohon dan serangga pada setiap petak pengamatan berukuran $20 \mathrm{~m} \times 20 \mathrm{~m}$, jenis perdu pada $10 \mathrm{~m} \times 10 \mathrm{~m}$, jenis semak $5 \mathrm{~m}$ x $5 \mathrm{~m}$ dan jenis rumput $2 \mathrm{~m} \times 2 \mathrm{~m}$. Jenis dan komposisi vegetasi dihitung dengan analisis vegetasi, sedangkan keanekaragaman serangga menggunakan indeks Shannon. Uji mangsa dilakukan untuk mengetahui preferensi burung insektivora terhadap serangga. Hasil penelitian menunjukkan bahwa komposisi vegetasi terdiri atas 7 spesies rumput, 20 spesies semak, 5 spesies perdu, dan 18 spesies pohon. Vegetasi tiap kelompok dengan indeks nilai penting (INP) tertinggi berturut-turut adalah Tectona grandis, Ipomoea sp., I. cylindrica, dan Panicum brevifolium. Keanekaragaman tertinggi kelompok vegetasi berturut-turut adalah semak $(2,430)$, pohon $(1,696)$, rumput $(1,680)$ dan perdu (1,364). Indeks keanekaragaman serangga adalah 2,572 dan belalang (ordo Orthoptera) adalah serangga yang paling disukai $L$. schach. Habitat burung insektivora $L$. schach memiliki karakteristik habitat yang didominasi $T$. grandis dan memiliki keanekaragaman semak yang tinggi.
\end{abstract}

Kata kunci: habitat, keanekaragaman, serangga, vegetasi, Lanius schach

\begin{abstract}
Insect diversity and vegetation structure are two aspects that affect the reproduction of insectivorous birds. The objective of this study was to investigate the characteristics of the original habitat Lanius schach in Tanjungsari of particularly the type, composition of vegetation, and preference to insect sprey. Observation of vegetation and insects were conduct using a combination methods of the track and checkered line on the transect along the $10 \mathrm{~km}$ (ten observation points). Insect and tree species were counted on plot (20 m x $20 \mathrm{~m})$, shrub (10 m x $10 \mathrm{~m})$, bush (5 m x $5 \mathrm{~m})$, and grass $(2 \mathrm{~m} \times 2 \mathrm{~m})$.Vegetation analysis was used to calculate the structure and composition of vegetation, whereas Shannon diversity index was used for insect diversity. Prey test was conducted to determine the preferences of insectivore birds on insects. The composition of the vegetation species consists of 7 grasses, 20 bushes, 5 shrubs and 18 trees. The dominant species of vegetation based on highest important value index was Tectona grandis, Ipomoea sp., I. cylindrica, and
\end{abstract}

*Penulis korespondensi: Fredy Lala. Balai Pengkajian Teknologi Pertanian Maluku Utara, Kompleks Pertanian Kusu, Oba Utara,

Kota Tidore Kepulauan, Maluku Utara 97800

Tel: 0921-3317980, Email: lalafredy@ymail.com 
Panicum brevifolium respectively. The highest diversity index of vegetation group were bush (2.430), tree (1.696), grass $(1,680)$, and shrubs (1.364), respectively. Insect diversity index was 2.572 and grasshoppers (Orthoptera) was the most preferred prey by L. schach. Overall, the habitat of insectivore birds L. schach are dominated by T. grandis, and has high diversity of bush.

Key words: habitat, diversity, insects, vegetation, Lanius schach

\section{PENDAHULUAN}

Keanekaragaman serangga dan struktur vegetasi suatu ekosistem adalah dua aspek penting yang mempengaruhi perkembangbiakan burung pemakan serangga (insektivora). Perkembangbiakan burung terkait erat dengan struktur vegetasi lokal pada suatu habitat tertentu (Herkert 1994; Delisle \& Savidge 1997). Di Amerika Serikat, menurunnya populasi burung selalu dihubungkan dengan terjadinya fragmentasi dan kehilangan habitat (Herkert 1995). Gangguan terhadap populasi burung juga dapat disebabkan oleh kegiatan perdagangan dan penangkapan secara ilegal, seperti yang terjadi di Medan, Sumatra Utara (Jepson \& Ladle 2005; Shepherd 2006).

Struktur suatu vegetasi sebagai habitat dan pendukung utama yang tak tergantikan sebagai sumber makanan serangga berperan penting dalam mempengaruhi kehidupan burung insektivora. Komunitas burung dari struktur vegetasi lapisan bawah hutan sekunder umumnya memanfaatkan sumber daya yang tersedia, seperti biji-biji dari berbagai jenis rumput dan semak (Novarino et al. 2005; Sadili 2010). Kelompok burung insektivora dijumpai paling banyak pada habitat hutan, persawahan, dan pemukiman (Rahayuningsih et al. 2010).

Komunitas burung dapat dibedakan menurut perbedaan lapisan hutan, yaitu stratum semak, antara semak dan pohon, dan tajuk hutan. Setiap stratum mempunyaikemampuanuntuk mendukung kehidupan burung. Burung insektivora umumnya terdapat pada stratum diantara semak dan pohon, biasanya merupakan tempat terbuka dan memiliki pohon-pohon rendah sampai tinggi. Pada stratum tersebut burung insektivora memiliki perilaku mencari mangsa lebih dari satu jenis (foraging generalis) (Mohan 1994), berpasangan saat musim kawin, dan beraktivitas lain untuk tetap survive, termasuk bersaing untuk mendapatkan tempat bertengger (Serrao 1969). Kajian karakteristik habitat dan perilaku burung insektivora memiliki relevansi dalam menentukan daerah baru yang mempunyai kemiripan struktur vegetasi dan keanekaragaman serangga. Kemiripan tersebut dapat membantu keberhasilan program introduksi burung insektivora.

Di Yogyakarta terdapat beberapa jenis burung yang memangsa serangga, salah satunya adalah bentet abu-abu (Lanius schach Linn.) yang berpotensi sebagai agens pengendalian hayati hama belalang kembara (Astuti et al. 2009) dan belalang pedang (Sexava spp.) (Lala et al. 2010). Informasi tentang karakteristik habitat asli burung L. schach di Tanjungsari belum tersedia sehingga penting untuk diteliti, terutama untuk mendukung program introduksinya ke daerah lain sebagai agens pengendalian hayati serangga hama.

Tujuan penelitian adalah untuk mengetahui karakteristik habitat asli burung L. schach di wilayah Tanjungsari yang meliputi jenis dan komposisi vegetasi serta preferensinya terhadap serangga mangsa.

\section{BAHAN DAN METODE}

Penelitian dilaksanakan dari bulan Februari 2012 sampai April 2012 di Kecamatan Tanjungsari, Kabupaten Gunungkidul, Provinsi Daerah Istimewa Yogyakarta. Survey menggunakan kendaraan (vehicle counts) (Sutherland et al. 2004) pada jalur sepanjang $10 \mathrm{~km}$. Pada setiap satu kilometer dilakukan pengamatan langsung terhadap serangga dan vegetasi.

\section{Pengamatan serangga dan uji mangsa}

Pengumpulan serangga dilakukan pada petak $20 \mathrm{~m} \times 20 \mathrm{~m}$ pada setiap titik pengamatan. Penangkapan serangga menggunakan jaring sebanyak 2 x 10 ayunan secara diagonal. Serangga yang tertangkap dibunuh menggunakan killing bottle kemudian diidentifikasi di Laboratorium Entomologi, Fakultas Pertanian, UGM Yogyakarta. 
Uji mangsa terhadap burung insektivora dilakukan pada beberapa serangga yang tertangkap di lokasi penelitian. Tiga individu burung $L$. schach yang sudah dilaparkan dimasukkan dalam sangkar kayu, berdinding kawat kasa, berukuran $100 \mathrm{~cm}$ x $100 \mathrm{~cm} \times 100 \mathrm{~cm}$ (1 individu dalam 1 kandang). Kemudian serangga Mecopoda sp., Tagasta marginella, Valanga nigricornis, Hyblaea puera, Rhynchoporus ferrugineus, Musca sp., dan Leptocorixa acuta dimasukkan dalam sangkar masing-masing sebanyak 5 (lima) individu. Komposisi kelima serangga tersebut sama untuk setiap ulangan. Satu jam kemudian dilakukan pengamatan terhadap jumlah serangga yang dimangsa burung insektivora. Uji dilakukan dari pukul 06:00 pagi sampai 12:00 siang WIB.

\section{Pengamatan dan penghitungan vegetasi}

Pengamatan dan penghitungan vegetasi dilakukan dengan kombinasi metode jalur dan garis berpetak (Kusmana 1997). Pada sepanjang jalur terdapat 10 titik pengamatan dengan jarak masingmasing titik $1 \mathrm{~km}$. Pada setiap titik pengamatan dibuat petak sesuai dengan jenis vegetasi yang diamati. Pada petak berukuran $20 \mathrm{~m}$ x $20 \mathrm{~m}$ diamati jenis pohon, petak $10 \mathrm{~m} \times 10 \mathrm{~m}$ diamati jenis perdu, petak $5 \mathrm{~m}$ x $5 \mathrm{~m}$ diamati jenis semak, dan petak $2 \mathrm{~m}$ x $2 \mathrm{~m}$ diamati jenis rumput. Parameter kuantitatif vegetasi yang diukur adalah kerapatan relatif(KR), frekuensi relatif(FR), dominasi relatif (DR), dan indeks nilai penting (INP) (Kusmana 1997). Nilai dominasi vegetasi semak didapatkan dengan mengukur dan menghitung luas tutupan kanopinya, sedangkan dominasi vegetasi rumput berdasarkan luas penuh tutupannya. Nilai dominasi pohon dan perdu diperoleh berdasarkan nilai basal area $(\mathrm{BA})$ dengan persamaan $\mathrm{BA}=(0,5 \mathrm{x} \mathrm{D})^{2} \mathrm{x}$ 3,14 , dimana $\mathrm{D}$ adalah diameter batang setinggi dada (cm) dan 3,14 adalah konstanta (Cox 1967). Keanekeragaman serangga dan vegetasi dihitung dengan menggunakan Shannon index (Ludwig \& Reynolds 1988).

\section{HASIL}

\section{Jenis dan jumlah serangga}

Berdasarkan hasil identifikasi dan klasifikasi di laboratorium diketahui bahwa jenis-jenis serangga di tempat penelitian beragam. Hal tersebut diketahui dari ditemukannya serangga dengan jumlah individu sebanyak 425 individu yang tergolong dalam 23 spesies, 19 famili, dan 7 ordo, dengan nilai indeks keanekaragaman sebesar 2,572. Serangga ordo Hemiptera dan Diptera adalah jenis terbanyak ( 5 spesies), sedangkan paling sedikit (1 spesies) adalah ordo Thysanoptera (Tabel 1).

\section{Preferensi mangsa oleh burung insektivora}

Hasil pengamatan menunjukkan bahwa preferensi burung insektivora terhadap serangga mangsa berbeda-beda. Spesies yang paling banyak dimangsa, yaitu T. marginella, $V$. nigricornis, dan H. puera masing-masing 5 individu atau $100 \%$, sedangkan paling sedikit adalah $R$. ferrugineus (1 individu atau 20\%). Ketiga spesies serangga yang paling disukai burung ini kebanyakan ditemukan pada daun tanaman padi gogo, rumput gajah, kacang-kacangan, akasia, dan jati. Dilihat dari tingkat ordo, Orthoptera adalah serangga yang paling banyak dimangsa, yaitu 12 individu dimangsa dari 15 individu yang diberikan, sedangkan paling sedikit ordo Coleoptera, yaitu 1 individu dimangsa dari 5 individu yang diberikan (Tabel 2).

\section{Jenis dan komposisi vegetasi}

Ditemukan 7 spesies vegetasi rumput dengan jumlah 546 individu. Spesies rumput dengan jumlah tertinggi adalah Cyperus kyllingia 144 individu (26,37\%), sedangkan spesies dengan jumlah terendah, yaitu Axonopus compressus dan Ottochloa graccilima masing-masing 18 individu (3,30\%). Pada kelompok vegetasi semak ditemukan 20 spesies dengan jumlah 1.898 individu. Spesies semak dengan jumah tertinggi adalah Imperata cylindrica dengan jumlah 324 individu (17,07\%), sedangkan terendah, yaitu Mikania micrantha dengan 2 individu $(0,11 \%)$. Kelompok vegetasi perdu hanya ditemukan 5 spesies dengan jumlah 525 individu. Ipomoea sp. merupakan spesies perdu dengan jumlah tertinggi, yaitu 214 individu (40,76\%), sedangkan Annona squamosa adalah spesies terendah, yaitu 6 individu (1,14\%). Pada kelompok pohon ditemukan 18 spesies dengan jumlah individu 499 pohon. Dari jumlah tersebut, pohon Tectona grandis merupakan spesies dengan jumlah tertinggi, yaitu 250 individu $(50,10 \%)$, sedangkan Syzygium samarangense, Swietenia 
Tabel 1. Keanekaragaman serangga yang ditemukan di Kecamatan Tangjungsari, Kabupaten Gunungkidul, DI Yogyakarta

\begin{tabular}{|c|c|c|c|}
\hline Ordo & Famili & Spesies & Jumlah \\
\hline \multirow[t]{4}{*}{ Orthoptera } & Tettigonidae & Holochlora sp. & 4 \\
\hline & & Mecopoda sp. & 8 \\
\hline & Acrididae & Valanga nigricornis & 24 \\
\hline & Blattidae & Periplaneta americana & 7 \\
\hline \multirow[t]{3}{*}{ Lepidoptera } & Noctuidae & Spodoptera sp. & 9 \\
\hline & & Plusia chalcites & 5 \\
\hline & Pyralidae & Ettiella sp. & 6 \\
\hline \multirow[t]{2}{*}{ Coleoptera } & Curculionidae & Rynchophorus ferrugineus & 6 \\
\hline & Bruchidae & Bruchus sp. & 14 \\
\hline \multirow[t]{3}{*}{ Hymenoptera } & Formicidae & Dolichoderus sp. & 16 \\
\hline & & Oecophylla smaragdina & 85 \\
\hline & Braconidae & Apanteles sp. & 7 \\
\hline \multirow[t]{5}{*}{ Diptera } & Cecidomyiidae & Orseoli oryzae & 6 \\
\hline & Muscidae & Musca sp. & 1 \\
\hline & Tephritidae & Procecidochares connexa & 6 \\
\hline & & Bactrocera sp. & 28 \\
\hline & Agromycidae & Agromyza phaseoli & 12 \\
\hline \multirow[t]{5}{*}{ Hemiptera } & Alydidae & Leptocoriza acuta & 4 \\
\hline & Plataspididae & Brachyplatys & 77 \\
\hline & Pentatomidae & Andrallus spinidens & 3 \\
\hline & Jassidae & Nephotettix virescens & 7 \\
\hline & Aphididae & Aphis sp. & 53 \\
\hline Thysanoptera & Thripidae & Thrips sp. & 37 \\
\hline Total & & & 425 \\
\hline
\end{tabular}

Tabel 2. Preferensi mangsa serangga oleh burung predator Lanius schach di Kecamatan Tangjungsari, Kabupaten Gunungkidul, DI Yogyakarta

\begin{tabular}{|c|c|c|c|c|c|}
\hline \multirow{2}{*}{ Ordo } & \multirow{2}{*}{ Famili } & \multirow{2}{*}{ Spesies } & \multicolumn{2}{|c|}{ Jumlah (individu) } & \multirow{2}{*}{$\%$} \\
\hline & & & Diberi & Dimakan & \\
\hline \multirow[t]{3}{*}{ Orthoptera } & Tettigonidae & Mecopoda sp. & 5 & 2 & 40 \\
\hline & Acrididae & T. marginella & 5 & 5 & 100 \\
\hline & & $V$. nigricornis & 5 & 5 & 100 \\
\hline Lepidoptera & Hyblaeidae & H. puera & 5 & 5 & 100 \\
\hline Coleoptera & Curculionidae & R. ferrugineus & 5 & 1 & 20 \\
\hline Diptera & Muscidae & Musca sp. & 5 & 3 & 60 \\
\hline Hemiptera & Alydidae & L. acuta & 5 & 3 & 60 \\
\hline
\end{tabular}

macrophylla, dan Persea americana adalah tiga spesies yang memiliki jumlah individu terendah yang sama, yaitu 1 individu $(0,20 \%)$ (Tabel 3$)$.

\section{Struktur vegetasi}

Hasil analisis vegetasi habitat menunjukkan sebaran vegetasi yang beragam. Sebaran jenis vegetasi per satuan luas tergambar dari variabel kerapatan relatif, frekuensi relatif, dominansi relatif, dan indeks nilai penting (INP). Berdasarkan nilai INP, rumput Panicum brevifolium adalah spesies yang dominan, sedangkan I. cylindrica, Ipomoea sp. dan T. grandis adalah spesies yang dominan pada vegetasi golongan semak, perdu, dan pohon. Dari hasil perhitungan nilai indeks Shannon diketahui bahwa vegetasi golongan semak memiliki tingkat keanekaragaman yang tinggi, sedangkan golongan rumput, perdu, dan pohon tingkat keanekaragamannya rendah (Tabel $3)$. 
Tabel 3. Analisis vegetasi rumput, semak, perdu, dan pohon di Kecamatan Tanjungsari, Kabupaten Gunungkidul, DI Yogyakarta

\begin{tabular}{|c|c|c|c|c|c|c|c|c|}
\hline Petak & Spesies & Famili & Jumlah & KR & FR & DR & INP & $H^{\prime}$ \\
\hline \multirow{8}{*}{$\begin{array}{l}2 \mathrm{~m} \times 2 \mathrm{~m} \\
\text { (Kelompok } \\
\text { Rumput) }\end{array}$} & Cynodon dactylon & Poaceae & 22 & 4,03 & 11,11 & 1,74 & 16,88 & \\
\hline & Cyperus kyllingia & Cyperaceae & 144 & 26,37 & 11,11 & 11,39 & 48,88 & \\
\hline & Paspalum sp. & Poaceae & 104 & 19,05 & 22,22 & 9,44 & 50,71 & \\
\hline & Panicum brevifolium & Poaceae & 140 & 25,64 & 11,11 & 18,71 & 55,46 & \\
\hline & Panicum repens & Poaceae & 100 & 18,32 & 11,11 & 23,65 & 53,08 & \\
\hline & Axonopus compressus & Poaceae & 18 & 3,30 & 22,22 & 18,69 & 44,21 & \\
\hline & Ottochloa gracillima & Poaceae & 18 & 3,30 & 11,11 & 16,38 & 30,78 & \\
\hline & Total & & 546 & 100 & 100 & 100 & & 1,680 \\
\hline \multirow{21}{*}{$\begin{array}{l}5 \mathrm{~m} \text { x } 5 \mathrm{~m} \\
\text { (Kelompok } \\
\text { Semak) }\end{array}$} & Borreria sp. & Rubiaceae & 292 & 15,39 & 7,14 & 6,27 & 28,80 & \\
\hline & Artemisia vulgaris & Asteraceae & 6 & 0,32 & 3,57 & 0,30 & 4,19 & \\
\hline & Galinsoga parviflora & Asteraceae & 22 & 1,16 & 3,57 & 0,85 & 5,58 & \\
\hline & Lantana camara & Verbenaceae & 60 & 3,16 & 3,57 & 3,11 & 9,85 & \\
\hline & Erigeron sumatrensis & Asteraceae & 58 & 3,06 & 5,36 & 4,26 & 12,68 & \\
\hline & Croton hirtus & Euphorbiaceae & 125 & 6,59 & 10,71 & 6,95 & 24,26 & \\
\hline & Erechtites sp. & Asteraceae & 8 & 0,42 & 1,79 & 0,55 & 2,76 & \\
\hline & Abrus sp. & Fabaceae & 20 & 1,05 & 1,79 & 0,73 & 3,57 & \\
\hline & Ageratum conyzoides & Asteraceae & 104 & 5,48 & 3,57 & 4,24 & 13,30 & \\
\hline & Chromolaena odorata & Asteraceae & 139 & 7,33 & 10,71 & 8,43 & 26,47 & \\
\hline & Bidens biternata & Asteraceae & 318 & 16,76 & 8,93 & 9,79 & 35,48 & \\
\hline & Alternanthera sp. & Amaranthaceae & 14 & 0,74 & 1,79 & 1,14 & 3,66 & \\
\hline & Clibadium surinamense & Asteraceae & 31 & 1,63 & 1,79 & 2,29 & 5,71 & \\
\hline & Imperata cylindrica & Poaceae & 324 & 17,08 & 10,71 & 17,51 & 45,30 & \\
\hline & Mikania micrantha & Asteraceae & 2 & 0,11 & 1,79 & 0,13 & 2,02 & \\
\hline & Drymaria cordata & Caryophyllaceae & 51 & 2,69 & 5,36 & 4,12 & 12,17 & \\
\hline & Nasturtium officinale & Brassicaceae & 60 & 3,16 & 1,79 & 6,57 & 11,52 & \\
\hline & Arachis sp. & Fabaceae & 32 & 1,69 & 5,36 & 10,80 & 17,84 & \\
\hline & Mimosa pudica & Fabaceae & 226 & 11,91 & 8,93 & 11,70 & 32,54 & \\
\hline & Commelina diffusa & Commelinaceae & 6 & 0,32 & 1,79 & 0,25 & 2,35 & \\
\hline & Total & & 1898 & 100 & 100 & 100 & & 2,430 \\
\hline \multirow{6}{*}{$\begin{array}{l}10 \mathrm{~m} \times 10 \mathrm{~m} \\
\text { (Kelompok } \\
\text { Perdu) }\end{array}$} & Pandanus sp. & Pandanaceae & 121 & 22,83 & 11,11 & 32,57 & 66,51 & \\
\hline & Ipomoea $\mathrm{sp}$. & Convolvulaceae & 214 & 40,38 & 22,22 & 7,80 & 70,40 & \\
\hline & Manihot utilissima & Euphorbiaceae & 102 & 19,25 & 38,89 & 4,13 & 62,27 & \\
\hline & Canna sp. & Cannaceae & 82 & 15,47 & 11,11 & 30,26 & 56,84 & \\
\hline & Annona squamosa & Annonaceae & 6 & 1,13 & 16,67 & 25,23 & 43,03 & \\
\hline & Total & & 525 & 100 & 100 & 100 & & 1,364 \\
\hline \multirow{19}{*}{$\begin{array}{l}20 \mathrm{~m} \text { x } 20 \mathrm{~m} \\
\text { (Kelompok } \\
\text { Pohon) }\end{array}$} & Acacia sp. & Fabaceae & 101 & 20,24 & 14,81 & 3,06 & 38,11 & \\
\hline & Baringtonia asiatica & Lecythidaceae & 9 & 1,80 & 1,85 & 3,61 & 7,26 & \\
\hline & Casuarina sp. & Casuarinaceae & 4 & 0,80 & 1,85 & 5,99 & 8,64 & \\
\hline & Tectona grandis & Lamiaceae & 250 & 50,10 & 16,67 & 5,24 & 72,01 & \\
\hline & Gliricidia maculata & Fabaceae & 23 & 4,61 & 5,56 & 2,93 & 13,10 & \\
\hline & Gnetum gnemon & Gnetaceae & 12 & 2,40 & 7,41 & 3,88 & 13,69 & \\
\hline & Mangifera indica & Anacardiaceae & 2 & 0,40 & 3,70 & 12,45 & 16,55 & \\
\hline & Cocos nucifera & Arecaceae & 14 & 2,81 & 9,26 & 6,60 & 18,67 & \\
\hline & Albizia falcataria & Fabaceae & 15 & 3,01 & 3,70 & 3,20 & 9,91 & \\
\hline & Leucaena leucocephala & Fabaceae & 12 & 2,40 & 5,56 & 3,54 & 11,50 & \\
\hline & Musa sp. & Musaceae & 42 & 8,42 & 9,26 & 4,35 & 22,03 & \\
\hline & Artocarpus altilis & Moraceae & 3 & 0,60 & 3,70 & 4,01 & 8,31 & \\
\hline & Carica papaya & Caricaceae & 2 & 0,40 & 3,70 & 2,79 & 6,89 & \\
\hline & Albizia saman & Fabaceae & 3 & 0,60 & 3,70 & 10,95 & 15,25 & \\
\hline & Bambuseae & Poaceae & 4 & 0,80 & 3,70 & 2,11 & 6,61 & \\
\hline & Syzygium samarangense & Myrtaceae & 1 & 0,20 & 1,85 & 2,24 & 4,29 & \\
\hline & Swietenia macrophylla & Meliaceae & 1 & 0,20 & 1,85 & 13,67 & 15,72 & \\
\hline & Persea americana & Lauraceae & 1 & 0,20 & 1,85 & 9,39 & 11,44 & \\
\hline & Total & & 499 & 100 & 100 & 100 & & 1,696 \\
\hline
\end{tabular}

KR: kerapatan relatif; FR: frekuensi relatif; DR: dominasi relatif; INP: indeks nilai penting, $H^{\prime}$ : Indeks keanekaragaman Shannon. 


\section{PEMBAHASAN}

Jumlah dan proporsi spesies masing-masing vegetasi tidak selalu berbanding lurus dengan jumlah individunya karena kerapatannya yang berbeda-beda. Adanya perbedaan kemampuan reproduksi, penyebaran, dan daya adaptasi terhadap lingkungan menjadi penyebab berbedanya nilai kerapatan dari masing-masing jenis dan golongan vegetasi (Arrijani et al. 2006). Rejpar \& Zakaria (2011) mengatakan bahwa karakter habitat, seperti komposisi vegetasi (tumbuhan di lahan berair, rumput, semak belukar, dan pohon) dan iklim mikro (temperatur, kelembaban relatif, intensitas cahaya) adalah faktor kunci yang mempengaruhi distribusi, keanekaragaman, dan kepadatan spesies burung.

Selain jumlah dan komposisi spesies, struktur vegetasi turut berpengaruh terhadap keanekaragaman serangga dan burung. Struktur vegetasi adalah sebaran individu dalam lapisan tajuk yang diartikan sebagai sebaran vegetasi per satuan luas (Heriyanto 2003). Crozie \& Niemi (2003) menyatakan bahwa struktur vegetasi yang bervariasi dari suatu habitat dapat mempengaruhi keanekaragaman jenis burung. Kelimpahan dan perkembangbiakan burung dapat dipengaruhi oleh ukuran vegetasi. Menurut Parish et al. (1994; 1995), jumlah dan tinggi pohon, tipe penggunaan lahan serta padatnya vegetasi sangat mempengaruhi kekayaan dan kelimpahan beberapa spesies burung. Demikian pula dengan upaya kombinasi tanaman pagar dengan habitat semi alami lain yang meningkatkan keragaman jenis struktur vegetasi, usaha pemeliharaan cover crop, pembatasan penggunaan herbisida, dan menghindari pemotongan pohon yang berlebihan (Hinsley \& Bellamy 2000). Apabila terjadi kerusakan habitat yang parah maka populasi burung akan berkurang dan kemungkinan punah, seperti yang terjadi pada burung Maleo di Sulawesi Utara (Gorog et al. 2005). Ketika pengamatan di lokasi penelitian, frekuensi teramatinya $L$. schach lebih sering pada habitat lahan kering polikultur dengan kerapatan pohon sedang sampai tinggi. Hal ini mirip dengan penelitian Azman et al. (2011) yang menyimpulkan bahwa keanekaragam relatif insektivora dan insektivora-frugivora adalah lebih tinggi di daerah padat pohon atau hutan sekunder dibandingkan dengan kawasan monokultur.
Dominannya pohon $T$. grandis, perdu Ipomoea sp., dan rumput $P$. brevifolium disebabkan oleh keanekaragaman vegetasi pohon, perdu, dan rumput yang rendah. Sebaliknya, semak I. cylindrica kurang dominan karena vegetasi semak memiliki keanekaragaman yang tinggi. Hal ini menunjukkan bahwa kondisi vegetasi, baik dominan maupun beragam dapat mempengaruhi pertumbuhan dan perkembangan serangga dan burung L. schach. Pohon jati (T. grandis) adalah vegetasi utama yang seringkali dimanfaatkan oleh burung insektivora dalam bertengger dan berteduh sekaligus tempat mencari dan memperoleh serangga mangsa berupa ulat jati (H. puera). Vegetasi yang bersama pohon jati mendominasi wilayah Tanjungsari adalah pohon Acacia sp., yang mempunyai percabangan banyak sehingga memudahkan burung insektivora dalam meletakkan sarang. Pada kedua pohon inilah seringkali dijumpai sarang dan aktivitas burung L. schach.

Tingkat keanekaragaman semak yang tinggi menunjukkan bahwa terdapat beragam sumber makanan yang tersedia bagi serangga. Hal ini akan menopang pertumbuhan dan perkembangbiakan serangga sehingga dapat meningkatkan populasi dan keanekaragamannya. Kondisi tersebut sangat menguntungkan burung $L$. schach karena memiliki sumber makanan yang banyak dan beragam.

Burung L. schach cenderung menyukai serangga belalang (Orthoptera) sebagai mangsa utama. Hasil uji mangsa menunjukkan bahwa dua spesies serangga ordo Orthoptera, yaitu $V$. nigricornis (Acrididae) dan T. marginella (Acrididae) termasuk jenis yang paling banyak dimangsa selain $H$. puera (Lepidoptera: Hyblaeidae). Prawiradilaga (1990), menyatakan bahwa serangga ordo Orthoptera adalah kelompok utama yang dimangsa oleh lebih dari seratus spesies burung disamping ordo Lepidoptera dan Coleoptera. Faktor yang menyebabkan kelompok serangga ini disukai oleh burung insektivora diduga karena tersedia dalam jumlah relatif banyak, ukuran tubuh yang mudah dilihat, dan relatif mudah diserang. Sundel et al. (2003) menyatakan bahwa preferensi predator terhadap mangsa didasari pada struktur anatomi mangsa, habitat dan perilaku mangsa. Implikasi penelitian ini dapat diterapkan pada bidang perlindungan tanaman khususnya pengendalian hayati serangga hama belalang. Bercocok tanam pada lahan kering dengan sistem polikultur sesuai 
dengan karakteristik habitat dan perilaku burung insektivora L. schach.

\section{KESIMPULAN}

Karakteristik habitat burung insektivora $L$. schach di Tanjungsari didominasi oleh $T$. grandis dengan keanekaragaman serangga dan vegetasi semak yang tinggi. Burung insektivora $L$. schach lebih menyukai serangga belalang ordo Orthoptera sebagai pakan.

\section{DAFTAR PUSTAKA}

Arrijani, Setiadi D, Guhardja E, Qayim I. 2006. Analisis vegetasi hulu DAS Cianjur Taman Nasional gunung Gede-Pangrango. Biodiversitas 7:147-153.

Astuti S, Untung K, Wagiman FX. 2009. Respons fungsional burung pentet (Lanius sp.) terhadap belalang kembara (Locusta migratoria manilensis). Jurnal Perlindungan Tanaman Indonesia 15:96-100.

Azman NM, Latip NSA, Sah SAM. 2011. Avian and feeding guilds in a secondary forest, an oil palm plantation and a paddy fields in riparian areas of the Kerian Rires Basin, Perak, Malaysia. Tropical Life Science Researce 22:45-64.

Cox GW. 1967. Laboratory Manual of General Ecology. Iowa: MC Crown.

Crozie GE, Niemi GJ. 2003. Using patch and landscape variables to model bird abundance in a naturally heterogenous landscape. Canadian Journal Zoology 81:441-452. doi: http://dx.doi. org/10.1139/z03-022.

Delisle JM, Savidge JA. 1997. Avian use and vegetation characteristics of conservation reserve program fields. Journal of Wildlife Management 61:318-325. doi: http://dx.doi. org/10.2307/3802587.

Gorog AJ, Pamungkas B, Lee RJ. 2005. Nesting ground abandoment by the Maleo (Macrocephalon maleo) in North Sulawesi: Identiffying concervation priorities for Indonesia's endemic megapode. Biological Conservation Journal 126:548-555. doi: http://dx.doi.org/10.1016/j. biocon.2005.07.006.

Heriyanto NM. 2003. Composition and forest stand burns in Berau, East Kalimantan. Bulletin Forest Research 639:1-5.

Herkert JR. 1994. The effect of habitat fragmentation on midwestern grassland bird communities.
Economical Applications 4:461-471. doi: http:// dx.doi.org/10.2307/1941950.

Herkert JR. 1995. An analisys of midwestern breeding bird population trends: 1966-1993. American Midland Naturalist 134:41-50. doi: http://dx.doi.org/10.2307/2426481.

Hinsley SA, Bellamy PE. 2000. The influence of hedge structure, management and landscape context on the value of hedgerous to birds: A review. Journal of Environmental Management 60:33-49. doi: http://dx.doi.org/10.1006/jema. 2000.0360 .

Jepson P, Ladle RJ. 2005. Bird-keeping in Indonesia: Conservation impact and the potential for substitution-based conservation responses. Oryx 39:1-6. doi: http://dx.doi.org/10.1017/S00306053 05001110 .

Kusmana C. 1997. Vegetation Survey Methods. Bogor: Institut Pertanian Bogor.

Lala F, Wagiman FX, Putra NS. 2010. Aktivitas harian dan preferensi burung predator Lanius sp. terhadap hama Sexava spp. Jurnal Perlindungan Tanaman Indonesia 16:22-27.

Ludwig JA, Reynolds JF. 1988. Statistical Ecology. A primer on Methods and Computing. New York: John Willey \& Sons.

Mohan D. 1994. Rufousbacked Shrike (Laniusschach Linne) feeding a Striped Keelback (Amphiesmastolata) to Cuckoo (Cuculuscanorus Linne) fledgeling. Journal of the Bombay Natural History Society 91:143-144.

Novarino W, Salsabila A, Jarulis. 2005. Struktur komunitas burung lapisan bawah pada daerah pinggiran hutan sekunder dataran rendah Sumatera Barat. Zoo Indonesia 29:51-58.

Parish T, Lakhami KH, Sparks TH. 1994. Modelling the relationship between bird populations variables and hedgerow and other field margin attributes. I. Species richness of winter, summer and breeding birds. Journal of Applied Ecology 31:764-775. doi: http://dx.doi.org/10.2307/2404166.

Parish T, Lakhami KH, Sparks TH. 1995. Modelling the relationship between bird populations variables and hedgerow and other field margin attributes. II. Abudance of individual species and of groups of similar species. Journal of Applied Ecology 32:362-371. doi: http://dx.doi. org/10.2307/2405102.

Prawiradilaga DM. 1990. Potensi burung dalam pengendalian populasi serangga hama. Media Konservasi 3:1-7.

Rahayuningsih M, Purnomo FA, Priyono B. 2010. Keanekaragaman burung di desa Karangasem, 
kecamatan Wirosari, kabupaten Grobogan, Jawa Tengah. Biosaintifika 2:82-89.

Rejpar MN, Zakaria M. 2011. Bird species abundance their correlationship with microclimate and habitat variables at natural wetland reserve, Peninsular Malaysia. International Journal of Zoology. doi: http://dx.doi.org/10.1155/2011/758573.

Sadili A. 2010. Struktur dan komposisi jenis tumbuhan herba dan semai pada habitat satwa herbivora di suaka margasatwa Cikepuh, Sukabumi, Jawa Barat. Jurnal Ilmu-ilmu Hayati 10:51-58.

Serrao JS. 1969. A curious play of Rufousbacked Shrikes. Newsletter for Birdwatchers 9:9-10.
Shepherd CR. 2006. The bird trade in Medan, North Sumatra: an overview. Birding Asia 5:16-24.

Sundel J, Eccard JA, Tiilikainen R, Ylonen H. 2003. Predation rate, prey preference and predator switching: experiments on voles and weales. Oikos 101:615-623. doi: http://dx.doi. org/10.1034/j.1600-0706.2003.12264.x.

Sutherland WJ, Newton I, Green RE. 2004. Bird Ecology and Conservation: A Handbook of Techniques. New York: Oxford University Press. doi: http://dx.doi.org/10.1093/acprof:o so/9780198520863.001.0001. 